\title{
O diferencial de salários de setores selecionados da indústria brasileira na atração do investimento estrangeiro direto no Brasil entre 1996 a 2009
}

\section{Giovani da Silva Oliveira}

Professor Substituto no Departamento de Engenharia de Produção da Universidade Tecnológica Federal do Paraná (UTFPR), Campus Londrina.

E-mail: gdoliveira@utfpr.edu.br

\section{Katy Maia}

Professora no Departamento de Economia da Universidade Estadual de Londrina (UEL)

E-mail: katymaia@terra.com.br

\section{Aricieri Devidé Júnior}

Professor no Departamento de Economia da Universidade Estadual de Londrina (UEL)

E-mail:aridjr@uel.br

Resumo: Este estudo estima uma função de produção Cobb-Douglas utilizando a metodologia de dados em painel. O objetivo foi analisar o investimento estrangeiro direto (IED) na indústria da transformação no Brasil no período de 1996 a 2009, observando sua interação com a mão de obra empregada e seus respectivos salários nos setores selecionados, bem como a influência da taxa Selic e a variação cambial. Os resultados sugerem que o fluxo de IED buscou aproveitar o diferencial de salários do trabalhador pouco qualificado e abundante no setor industrial, bem como a importância da política monetária na atração de IED no Brasil após o Plano Real.

Palavras chaves: Investimento estrangeiro direto, Movimento de capital de longo prazo, Crescimento econômico para economias abertas

Abstract:This study estimates a Cobb-Douglas production function using panel data methodology. The aim was to analyze foreign direct investment (FDI) in the manufacturing industry in Brazil in the 1996-2009 period, observing its interaction with the workforce employed and their respective wages in the selected sectors, as well as the influence of the Selic rate and the exchange rate. The results suggest that FDI flow sought to take advantage of the little qualified worker's wages differential and abundant in the industrial sector, and of the importance of monetary policy in attracting FDI in Brazil after the Real Plan.

Key words: Foreign direct investment, Long-term capital movement, Economic growth for open economies. 
p. 19 - O diferencial de salários de setores selecionados da indústria brasileira na atração do investimento estrangeiro direto no Brasil entre 1996 a 2009

\section{INTRODUÇÃO}

O movimento de capitais de longo prazo nas últimas décadas - 1980 a 2010 entre economias desenvolvidas e em desenvolvimento teve seu reflexo no mercado de trabalho do Brasil, especificamente na oferta de mão de obra. Mudanças estruturais e de intercâmbios tecnológicos são consequências do processo de globalização. No longo prazo, a mobilidade do capital, além de aumentar o acesso a tecnologias desenvolvidas em outros mercados, levou à promoção do crescimento econômico em mercados emergentes.

A partir do início dos anos 80, segundo Krugman e Obstfeld (2010), esses capitais de longo prazo moveram-se em direção aos países da Europa Oriental e da Ásia e permitiram o desenvolvimento das economias com grandes mercados consumidores, composto por mão de obra barata e alguma infraestrutura.

No Brasil, a abertura da conta de capital, a partir de 1990, facilitou a mobilidade do capital internacional, ao atrair expressivo nível de investimento estrangeiro direto (IED). O objetivo das mudanças estruturais efetuadas pelo governo brasileiro no início dos anos 90 foi atrair o fluxo de capital de longo prazo e modernizar a economia. 0 resultado contribuiu, por um lado, para maior integração tecnológica com outras economias mundiais, e, por outro, para maior vulnerabilidade a crises econômicas externas. Simonsen e Cysne (2007) destacam a existência de três maneiras de aporte do Investimento: (i) fusões ou aquisições (F\&A) de empresas; (ii) formação bruta de capital fixo (FBCF); (iii) investimento em portfólio. Considera-se a FBCF mais saudável para as economias receptoras, pois se trata de investimentos a partir da planta, também chamada de greenfield.

Os resultados das mudanças estruturais na economia brasileira deram resposta logo nos primeiros anos da década de 1990, segundo Carneiro (2002), com o aumento do ingresso de IED, principalmente nos setores das telecomunicações e equipamentos eletrônicos. O autor comenta ainda que a atração desses capitais se deu por meio de incentivos, como exemplo, a alta rentabilidade (taxas de juros elevadas), processo de privatizações, incentivos fiscais e acesso a matérias-primas, mão de obra barata e diferenciais de salários menores se comparados aos dos países desenvolvidos. Vários autores escreveram sobre o ingresso de IED no Brasil (FRANCO, 2005; IEDI, 2006; LAPLANE; SARTI, 1999; IPEA, 2010; JORGE, 2007; RIBEIRO, 2006).

Sob esta ótica, surgem algumas questões que merecem ser investigadas: qual foi a distribuição do IED por setor na indústria de transformação do Brasil nos anos de 1996 a 2009? Quais foram os principais países investidores por origem dos recursos?

Este trabalho tem como objetivo geral analisar o investimento estrangeiro direto (IED) na indústria da transformação no Brasil no período de 1996 a 2009, observando sua interação com a mão de obra empregada e seus respectivos salários nos setores selecionados, bem como a influência da taxa Selic e a variação cambial. Busca-se compreender quais fatores são os determinantes do fluxo de IED que podem contribuir com as políticas públicas, para que o fluxo de capitais de longo prazo promova desenvolvimento mais equitativo entre os setores da indústria de transformação no Brasil. 
Cabe destacar que para esta pesquisa foram selecionados aqueles setores da instria de transformação que receberam mais de $1 \%$ de investimento estrangeiro direto no período analisado.

\section{REVISÃO DA LITERATURA}

\subsection{O modelo teórico de Vu e Noy}

O modelo teórico utilizado nesta pesquisa foi adaptado do trabalho de Vu e Noy (2009). Os autores adotam um modelo de crescimento endógeno, formalizado por uma função de produção Cobb-Douglas modificada. A fim de estimar o impacto do investimento estrangeiro direto no crescimento econômico de países da Organização para Cooperação e Desenvolvimento Econômico (OCDE), os autores utilizam-se de dados setoriais, e assim, observaram duas formas de interação entre o IED e o crescimento econômico: diretamente, por meio do crescimento do PIB e também, indiretamente, por meio da sua interação com o mercado de trabalho. Entretanto, destacam que o efeito não é igualmente distribuído entre países e setores. A interação pode depender apenas da correlação positiva entre IED e o crescimento em um número limitado de setores.

Neste modelo de crescimento, versão modificada, Vu e Noy (2009) consideraram as seguintes variáveis independentes: tecnologia, capital, trabalho, IED, além de um vetor de variáveis auxiliares. Os autores comentam que, a partir da teoria desenvolvida, as pesquisas que buscam observar os efeitos dos fluxos de IED focam seu impacto sobre a produção e produtividade. No entanto, maior atenção recai sobre as interações dos fluxos de IED com o capital humano e o nível de tecnologia do país receptor. No modelo teórico desenvolvido pelos autores, a função de produção Cobb-Douglas modificada assume a seguinte forma quando logaritmizada:

$$
\begin{aligned}
& g Y_{i c t}=\ln A+\alpha \ln L_{i c t}+\beta \ln K_{i c t}+\gamma \ln F_{i c t}+ \\
& \sum_{j=1}^{n} \varphi \ln C_{i c t}+\sum_{k=1}^{m} \psi Z_{i c t}+v_{i}+a_{c}+e_{t}+\varepsilon_{i c t}
\end{aligned}
$$

A variável dependente do modelo, $g Y_{i c t}$, é a taxa de crescimento do valor adicionado para os setores de atividades; as variáveis: $L, K$ e $F$, são respectivamente, o trabalho, capital doméstico e capital externo. A Identificação desse último componente é composta pelo estoque de capital e o fluxo de IED. A variável $C$ representa o vetor das variáveis de controle utilizadas no modelo em sua forma logarítmica. A variável $Z$ indica um vetor das variáveis em nível por país específico ao nível de variáveis. Os índices $i, c$ e $t$ denotam, o setor, o país e o ano, respectivamente. A variável $v_{i}$ é a perturbação específica que ocorre em cada setor, $a_{c}$ é o distúrbio específico de cada país, $e_{t}$ é o distúrbio do período em análise e, finalmente, $\varepsilon_{i c t}$ é o distúrbio idiossincrático.

Destaca-se que todos os coeficientes são individualmente menores que a unidade, no entanto, a soma deles não é necessariamente a unidade, uma vez que os retornos constantes de escala não são assumidos no modelo ampliado da função de 
p. 21 - O diferencial de salários de setores selecionados da indústria brasileira na atração do investimento estrangeiro direto no Brasil entre 1996 a 2009

produção Cobb-Douglas. Para avaliar a interação entre IED e o capital humano, Vu e Noy (2009) adotaram o coeficiente do mercado de trabalho, como:

$$
\alpha=\alpha_{1} \ln L i c t+a_{2} \ln F_{i c t}
$$

Ao substituir a equação (1.1) na equação (1), tem-se:

$$
\begin{aligned}
& g Y_{i c t}=\ln A+\alpha_{1} \ln L_{i c t}+\alpha_{2} \ln F_{i c t}+\beta \ln K_{i c t}+\gamma \ln F_{i c t}+ \\
& \sum_{j=1}^{n} \emptyset_{j} \ln C_{i c t}+\sum_{k=1}^{m} \psi_{k} \ln Z_{i c t}++v_{i}+a_{c}+e_{t}+\varepsilon_{i c t}
\end{aligned}
$$

Ao convertermos a equação (2) para o modelo empírico, desenvolvido pelos autores, obtém-se a equação que descreve os efeitos agregados do IED:

$$
\begin{aligned}
& V A L_{i c t}=\beta_{1}+\beta_{2} L A B_{i c t}+\beta_{3} I E D_{i c t_{2}}+\beta_{4} I E D L A B_{i c t}+\beta_{5} C A P_{i c t}+ \\
& \sum_{j=1}^{n} \beta_{j} C O N_{i c t}+v_{i}+a_{c}+e_{t}+\varepsilon_{i c t}
\end{aligned}
$$

Tem-se que, $V A L$ é a taxa de crescimento do Valor Adicionado, $L A B$ é o logaritmo do registro do mercado de trabalho, $I E D$ é o termo log do investimento estrangeiro direto, $I E D L A B$ é o termo $\log$ da interação entre o $I E D$ e o registro do mercado de trabalho, $C A P$ é o termo log para o capital interno, $C O N$ é o termo logaritmizado que contém as variáveis de controle. A equação (4) informa como foram calculados os efeitos setoriais do IED:

$$
\begin{gathered}
V A L_{i c t}=\beta_{1}+\beta_{2} L A B_{i c t}+\beta_{3} I_{E D_{i c t}}+\beta_{4} I E D L A B_{i c t}+\beta_{5} C A P_{i c t}+ \\
\sum_{i=1}^{11} \delta_{i} S_{i} I E D_{i c t}+\sum_{i=1}^{11} \eta_{i} S_{i} I E D L A B_{i c t}+\sum_{j=1}^{n} \beta_{i} C O N_{i c t}+v_{i}+a_{c}+e_{t} \\
+\varepsilon_{i c t}
\end{gathered}
$$

Sendo que o termo $\delta_{i}$ é o termo que indica as dummies setoriais $i=1,2, \ldots, 11$, ou seja, revela o efeito do $\beta_{3}$ no setor base e $\left(\beta_{3}+\delta_{i}\right)$ em cada um dos 11 setores. Similarmente, $\eta_{i}$ e $\zeta_{i}$ são os termos de interação, $\beta_{4}$ mensura o efeito do IEDLAB no setor base e $\left(\beta_{4}+\eta_{i} S_{i}\right)$ em cada um dos 11 setores selecionados.

A aplicação do modelo inicia com a estimação da equação (4), a fim de serem observados os efeitos agregados do IED. Primeiramente, são avaliadas as variáveis usadas em Romer (2001 apud VU; NOY, 2009). Em seguida, as variáveis são gradualmente eliminadas por meio dos testes de multicolinearidade. Inicialmente o modelo é estimado 
sem o termo de interação. Como primeiro passo, usam-se os mínimos quadrados ordinários (MQO) com variáveis dummy para controlar a autocorrelação e o ajustamento da heteroscedasticidade, chamado de "White Correction".

Os resultados, segundo Vu e Noy (2009), mostram que o IED tem efeito positivo e não estatisticamente discernível, sobre o crescimento econômico, através de sua interação com o mercado de trabalho. A utilização deste modelo se justifica na tentativa de observar empiricamente como o IED interage com qualidade da mão de obra utilizada na indústria de transformação e, assim, identificar padrões entre os setores.

\section{PERFIL DO INVESTIMENTO ESTRANGEIRO DIRETO NO BRASIL EM ANOS RECENTES}

Pode-se observar na Figura 1, a qual mostra o total de Investimento Estrangeiro Direto no Brasil entre os anos de 1990 a 2010, a importância das políticas internas que, a partir de 2003, repercutiram positivamente no ambiente externo e mais investimentos estrangeiros diretos foram direcionados à economia brasileira.

Figura 1 - Total de Investimento Estrangeiro Direto no Brasil, 1990 a 2010 (bilhões US\$)

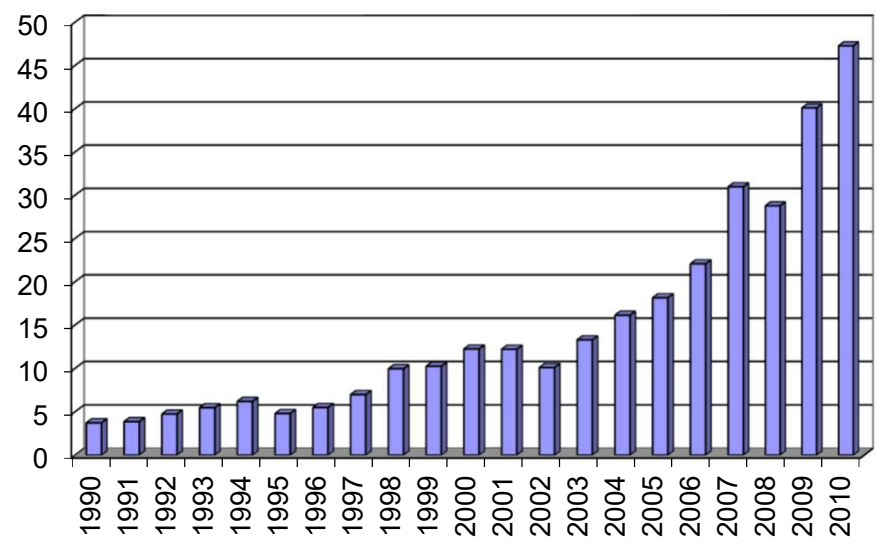

Nota: Valores em milhões de US\$, a preços correntes e a taxas de câmbio correntes. Fonte: Adaptada de United Nations Conference on Trade and Development (2013).

A Figura 2 mostra a distribuição (\%) do IED por atividade econômica principal no Brasil para o período de 1995 a 2009. É importante frisar que as duas primeiras colunas informam, respectivamente, os anos de 1995 e 2000, são dados que representam o estoque de IED que cada setor de atividade econômica no Brasil recebeu. Já os dados entre os anos de 2001 a 2009 representam os fluxos anuais do IED. A disponibilidade de dados obedece aos divulgados pelo Censo de Capitais Estrangeiros (BACEN, 2013).

Segundo o Censo de Capitais Estrangeiros do BACEN o setor industrial brasileiro registrou em sua conta de estoque de IED em 1995, incremento de 66,9\% direcionado ao Brasil. Esse aporte financeiro, segundo Gonçalves (2005), está relacionado com a abertura da economia brasileira ao produto importado, fato que ocorre em detrimento do produto de fabricação nacional, porém auxiliou na promoção do contato tecnológico e econômico do Brasil com as economias desenvolvidas. 
p. 23 - O diferencial de salários de setores selecionados da indústria brasileira na atração do investimento estrangeiro direto no Brasil entre 1996 a 2009

Esse movimento migratório do capital estrangeiro, segundo Bresser-Pereira e Marconi (2008), está ligado ao risco de desindustrialização causada pela sobreapreciação da taxa real de câmbio, cuja origem está na política de crescimento com poupança externa e na doença holandesa ${ }^{1}$.

Figura 2 - Distribuição (\%) do IED por atividade econômica principal, Brasil, 1995 a 2009

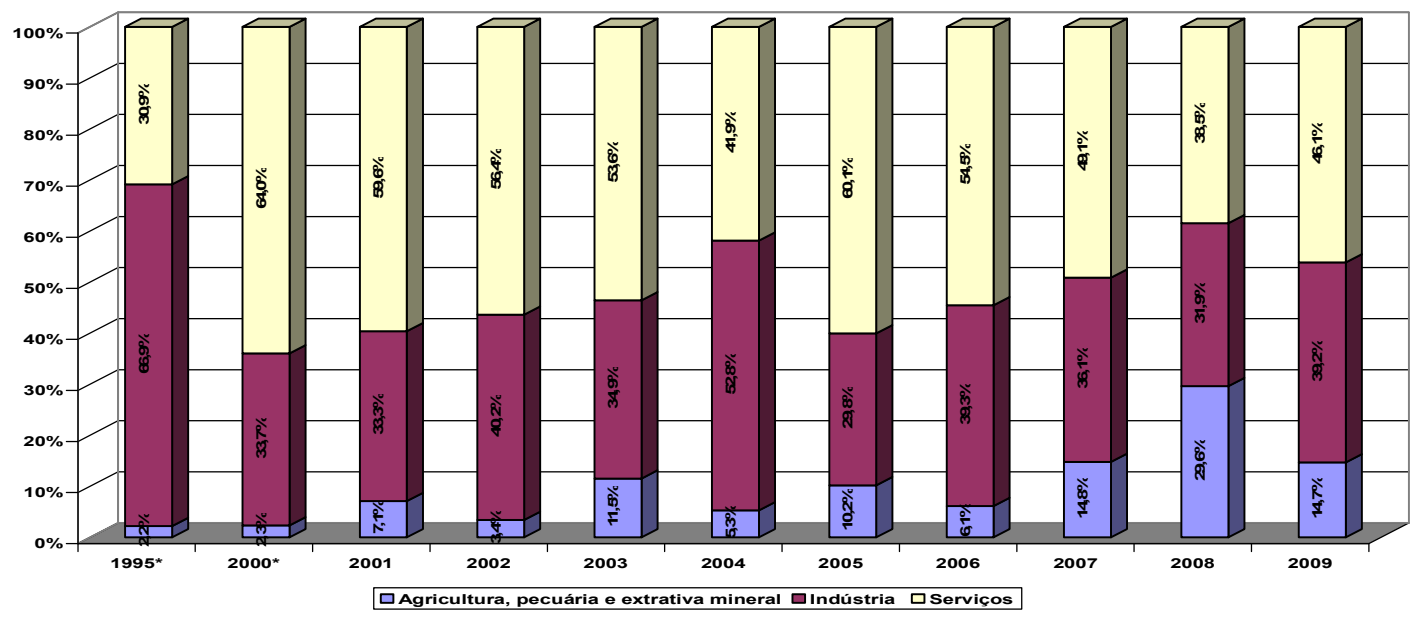

Fonte: Elaborado pelo autor, a partir dos dados do BACEN (2013).

Nota: *Refere-se ao estoque de IED.

Ao analisar os demais anos, destacam-se os fluxos registrados no ano de 2004, quando o setor industrial recebeu 52,8\% do IED direcionado à economia brasileira. Após esse ano, segundo Araújo, Bruno e Pimentel (2012), o setor industrial perdeu participação relativa, justamente quando a economia brasileira apresentava as taxas mais altas de crescimento. Segundo os autores essa perda de participação relativa que ocorre no setor industrial, apesar da modernização das plantas, foi favorecida pela importação de bens de capital e dos elevados ganhos de produtividade.

Em razão desta pesquisa analisar a indústria de transformação no Brasil, optou-se por considerar a distribuição do IED por setores de atividades levando-se em consideração a denominação da CNAE, para a divisão até dois dígitos.

Na Tabela 1 é apresentada a distribuição (\%) do IED no setor da indústria da transformação no Brasil para o período de 1996 a 2009. Cabe ressaltar que após a tabulação desses dados, os mesmos serviram de base para a decisão de agrupamento setorial e respectiva análise empírica, uma vez que os dados correspondem a 96,24\% do IED direcionado à economia brasileira no período.

\footnotetext{
${ }^{1}$ A doença holandesa "é um fenômeno decorrente da existência de recursos naturais abundantes que geram vantagens comparativas ao país que os possui e, segundo os mecanismos de mercado, podem levá-lo a se especializar na produção destes bens e não se industrializar ou terminar se desindustrializando, o que inibiria o processo de desenvolvimento econômico" (BRESSER-PEREIRA; MARCONI, 2008, p. 7).
} 
Tabela 1 - Distribuição (\%) do IED no setor da Indústria da Transformação no Brasil entre 1996 a 2009

\begin{tabular}{l|l|c}
\hline Código & \multicolumn{1}{|c}{ Denominação do setor } & Distribuição \% \\
\hline 1 & Fabricação de Produtos Alimentícios e Bebidas & 18,16 \\
8 & Metalurgia & 17,43 \\
13 & Fabricação e Montagem de Veículos Automotores, Reboques e Carrocerias. & 14,46 \\
5 & Fabricação de Produtos Químicos & 13,33 \\
10 & Fabricação de Equipamentos de Informática, Produtos Eletrônicos e Ópticos. & 6,59 \\
4 & Fabricação de Coque, Refino de Petróleo, Elaboração de Combustíveis. & 4,64 \\
12 & Fabricação de Máquinas e Equipamentos & 4,47 \\
3 & Fabricação de Celulose, Papel e Produtos de Papel. & 3,86 \\
6 & Fabricação de Artigos de Borracha e Plástico & 3,51 \\
11 & Fabricação de Máquinas, Aparelhos e Materiais Elétricos. & 3,20 \\
7 & Fabricação de Produtos de Minerais Não Metálicos & 2,67 \\
2 & Fabricação de Produtos Têxteis e Acessórios & 1,66 \\
14 & Fabricação de Outros Equipamentos de Transporte & 1,36 \\
9 & Fabricação de Produtos de Metal - Exclusive Máquinas e Equipamentos & 1,07 \\
\hline & Total & $96,24 \%$ \\
\hline
\end{tabular}

Fonte: Adaptado de BACEN (2013).

Os setores que receberam maior aporte financeiro internacional foram: Fabricação de Produtos Alimentícios e Bebidas, Metalurgia Básica e Fabricação e Montagem de veículos automotores, reboques e carrocerias, com 18, 17 e 14\%, respectivamente. O primeiro setor é formado por mão de obra abundante, mas com baixa qualificação, enquanto os outros dois setores, apesar de empregarem menos trabalhadores demanda maior qualificação da mão de obra.

Cabe destacar que estes valores balizaram a pesquisa no sentido de que foram analisados os setores que receberam mais de $1 \%$ de fluxo de IED. Assim, foram excluídos os setores: Edição, Impressão e Reprodução de Gravações; Preparação de Couros e Fabricação de artefatos de Couro, Artigos de Couro e Calçados; Fabricação de produtos de Madeira; Fabricação de Móveis e Indústrias Diversas.

A Tabela 2 mostra o fluxo do IED, segundo o país de origem dos recursos em (\%), no Brasil para os anos de 1995, 2000, 2005 e 2010, de acordo com os dados do Censo de Capitais do BACEN. Pode-se verificar que os EUA é o país que mais realiza IED no Brasil. Apesar de sua histórica importância para a economia brasileira, este país vem perdendo gradualmente participação na composição dos recursos, registrando $26 \%$, 23\% e 16\%, respectivamente. O contrário acontece com os Países Baixos (Holanda) que no ano de 1995 formalizaram 3,7\% do total de IED para o Brasil, já nos censos de 2000 e 2005, passaram a participar com 10,7\% e 16,6\% do total de investimentos estrangeiros diretos, respectivamente. 
p. 25 - O diferencial de salários de setores selecionados da indústria brasileira na atração do investimento estrangeiro direto no Brasil entre 1996 a 2009

Tabela 2 - IED no Brasil, por país de origem dos recursos em (\%) - 1995, 2000, 2005 e 2010

\begin{tabular}{|c|c|c|c|c|c|c|c|}
\hline \multicolumn{2}{|l|}{1995} & \multicolumn{2}{|l|}{2000} & \multicolumn{2}{|l|}{2005} & \multicolumn{2}{|l|}{2010} \\
\hline $\begin{array}{c}\text { País Origem dos } \\
\text { Recursos }\end{array}$ & $\%$ & $\begin{array}{c}\text { País Origem dos } \\
\text { Recursos }\end{array}$ & $\%$ & $\begin{array}{c}\text { País Origem dos } \\
\text { Recursos }\end{array}$ & $\%$ & $\begin{array}{c}\text { País Origem dos } \\
\text { Recursos }\end{array}$ & $\%$ \\
\hline Alemanha & 13,98 & Espanha & 11,89 & Países Baixos & 16,59 & Estados Unidos & 18,40 \\
\hline Suíça & 6,75 & $\begin{array}{l}\text { Países Baixos } \\
\text { (Holanda) }\end{array}$ & 10,73 & Espanha & 10,80 & Espanha & 12,26 \\
\hline $\begin{array}{l}\text { Diversos } \\
\text { Estrangeiros }\end{array}$ & 5,16 & Cayman, Ilhas & 6,04 & França & 7,52 & França & 4,87 \\
\hline França & 4,87 & Alemanha & 4,96 & Alemanha & 4,45 & Luxemburgo & 5,13 \\
\hline Reino Unido & 4,47 & Portugal & 4,38 & Brasil & 4,45 & Reino Unido & 2,73 \\
\hline Canadá & 4,36 & $\begin{array}{l}\text { Diversos } \\
\text { Estrangeiros }\end{array}$ & 3,24 & Canadá & 4,11 & Canadá & 2,33 \\
\hline Itália & 3,02 & Itália & 2,43 & Ilhas Virgens (GB) & 2,96 & México & 2,71 \\
\hline Demais Países & 21,28 & Demais Países & 22,70 & Demais Países & 19,45 & Demais Países & 16,30 \\
\hline Total & 100,00 & Total & 100,00 & Total & 100,00 & Total & 100,00 \\
\hline
\end{tabular}

Fonte: Adaptado de BACEN (2013).

De acordo com o último Censo de Capitais do Bacen, para o ano de 2010, verificou-se que os Países Baixos (Holanda) já participam com 27,81\% do IED direcionado à economia brasileira, enquanto os Estados Unidos aparecem com 18,40\%, seguido pela Espanha com 12,26\%.

\section{ESTRATÉGIA EMPÍRICA}

\subsection{Fontes de dados}

O estudo foi desenvolvido por meio da coleta e análise de dados secundários disponibilizados por pesquisas ligadas ao governo federal, sendo eles: (i) Investimento Estrangeiro Direto, divulgado pelo Banco Central do Brasil (BACEN); (ii) Relações Anuais das Informações Sociais (RAIS) do Ministério do Trabalho e Emprego (M.T.E.); (iii) Pesquisa Industrial Anual (PIA) do Instituto Brasileiro de Geografia e Estatística (IBGE); (iv) Instituto de Pesquisa Econômica Aplicada (IPEA). A base de dados consultada junto ao Banco Central do Brasil (BACEN) é composta pelas informações divulgadas pela Diretoria de Fiscalização (Difis) - do Departamento de Combate a llícitos Financeiros e de Supervisão de Câmbio e Capitais Internacionais - Investimentos Estrangeiros Diretos, segundo distribuição por Atividade Econômica de Aplicação de Recursos. Os fluxos de IED correspondem aos valores informados entre os anos de 1996 a 2009. Foram, também, coletados os valores da Taxa Selic ${ }^{2}$, por meio de consulta ao Sistema de Metas de Inflação

\footnotetext{
2 Segundo Assaf Neto (2013, p. 64) "a taxa Selic representa a média de juros das operações diárias de financiamentos realizadas pelas instituições no mercado monetário, sendo as operações lastreadas em Títulos Públicos Federais. Os negócios são registrados e controlados pelo Sistema Especial de Liquidação e Custódia (Selic)". Para fins deste estudo utilizou-se a média da taxa Selic anualizada. Somou-se as taxas determinadas pelo Comitê de Política Monetária (Copom), realizadas pelo Banco Central do Brasil, em seguida as mesmas foram divididas pelo número de reuniões realizadas entre os anos de 1996 a 2009.
} 
e da Taxa de câmbio comercial para compra: real (R\$) / dólar americano (US\$) - fim período.

A extração dos dados sobre vínculo empregatício da RAIS tem por objetivo identificar também a escolaridade dos trabalhadores na indústria de transformação. A escolaridade foi utilizada como proxy do capital humano. Para esta pesquisa, optou-se por classificar os trabalhadores em dois grupos: trabalhadores menos qualificados, aqueles com grau de instrução que engloba desde analfabetos até os que possuem ensino médio completo; trabalhadores mais qualificados, aqueles que possuem curso superior incompleto ou completo. Cabe destacar que este último grupo engloba os trabalhadores com mestrado e doutorado. O Quadro 1 apresenta agregação da escolaridade realizada para este estudo. Cabe destacar que os trabalhadores qualificados são aqueles com 15 anos ou mais de estudo e os menos qualificados aqueles com até 14 anos de estudo.

Quadro 1 - Níveis de Escolaridade da mão de obra

\begin{tabular}{|c|c|c|}
\hline $\begin{array}{l}\text { Grau de Instrução de } \\
1985 \text { a } 2005\end{array}$ & $\begin{array}{l}\text { Escolaridade Agregada } \\
\text { após } 2005\end{array}$ & Classificação \\
\hline $\begin{array}{l}\text { Analfabeto } \\
\text { Até 4ạ Série Completa }\end{array}$ & $\begin{array}{l}\text { Analfabeto } \\
\text { Até a 5a Série do Fundamental }\end{array}$ & \multirow{3}{*}{$\begin{array}{l}\text { Mão de obra menos } \\
\text { qualificada }\end{array}$} \\
\hline $\begin{array}{l}\text { 8a Série Incompleta } \\
\text { 8a Série Completa }\end{array}$ & $\begin{array}{l}\text { 6a ao 9o ano do Fundamental } \\
\text { Incompleto } \\
\text { 9o ano do Fundamental Completo }\end{array}$ & \\
\hline $\begin{array}{l}\text { 2 Grau Incompleto } \\
\text { 2o Grau Completo }\end{array}$ & $\begin{array}{l}\text { Ensino Médio Incompleto } \\
\text { Ensino Médio Completo }\end{array}$ & \\
\hline $\begin{array}{l}\text { Superior Incompleto } \\
\text { Superior Completo }\end{array}$ & $\begin{array}{l}\text { Superior Incompleto } \\
\text { Superior Completo }\end{array}$ & Mão de obra Qualificada \\
\hline
\end{tabular}

Fonte: Adaptado da RAIS (BRASIL, 2012).

O valor total da produção industrial (VTP) dos setores selecionados será utilizado como variável dependente no modelo empírico aplicado. Optou-se pelo uso desta variável a fim de identificar as características nas relações entre o crescimento econômico dos setores e preencher uma lacuna existente sobre os determinantes do IED no Brasil, bem como a qualificação da mão de obra empregada nos setores que receberam fluxo de IED. Dessa forma, espera-se contribuir com a literatura nacional ao utilizar a abordagem empírica baseada em dados em painel. O conceito da variável dependente no modelo empírico é (VTP):

- Valor bruto da produção industrial: obtido pela soma de vendas de produtos e serviços e em elaboração, e produção própria realizada para o ativo imobilizado.

Já as variáveis que compõem o capital interno, ou seja, o que se assume ser o investimento nacional é a soma dos valores monetários dos seguintes conceitos:

- Estoque de produtos acabados e em elaboração em 31.12 do ano de referência: de acordo com o método de valoração para fins fiscais; esta variável inclui o valor dos estoques de produtos de propriedade da empresa que se encontra em poder de terceiros ou em trânsito e não inclui o valor dos estoques de produtos de propriedade da empresa que se encontram na mesma. 
p. 27 - O diferencial de salários de setores selecionados da indústria brasileira na atração do investimento estrangeiro direto no Brasil entre 1996 a 2009

- Estoque de matérias-primas, materiais auxiliares e componentes em 31.12 do ano de referência: de acordo com o método de valoração adotado para fins fiscais, incluem-se também nesta variável o material de embalagem, combustível usados como matéria-prima e lubrificantes na data de 31.12 .

- Valor da transformação industrial (VTI): esta variável informa a diferença entre o valor bruto da produção industrial e o custo das operações industriais.

A fim de complementar os valores do capital interno, optou-se por consultar e incorporar os valores monetários de outras duas tabelas. A Tabela 1996 que informa aquisições, melhorias e baixas no ativo imobilizado das empresas industriais com cinco ou mais pessoas ocupadas, segundo as divisões e os grupos de atividades (CNAE 1.0). Desta tabela foram coletados dados para o período de 1996 a 2006. Para os anos de 2007 a 2009, valores que correspondem à CNAE 2.0, foram coletados dados da Tabela 1843. As variáveis consultadas foram:

- Ativo imobilizado - Aquisições - Valor: corresponde ao custo das aquisições e da produção própria para o ativo imobilizado.

- Ativo imobilizado - Melhorias - Valor: corresponde ao custo das melhorias para o ativo imobilizado. São consideradas como melhorias as benfeitorias e os melhoramentos.

Após a coleta individual dos dados foi realizada agregação dos mesmos. Antes da agregação, os valores foram deflacionados pelo IPCA e transformados em valores reais de 2009, conforme procedimento descrito anteriormente. Os dados utilizados como variável de controle (energia), no modelo empírico foram coletadas também junto às Tabelas 1996 e 1843, seguindo a mesma definição de consulta, descrita acima. A variável possui a seguinte definição:

- Compra de energia elétrica e consumo de combustível: gastos relacionados com os custos diretos de produção industrial, a título de compra de energia elétrica e consumo de combustíveis usados para acionar maquinaria e para aquecimento.

Além da variável de controle citada anteriormente, foi incluída uma variável dummy para o regime cambial vigente no período analisado. No Brasil adotou-se o regime de câmbio fixo até dezembro de 1998, após, passou-se ao regime de câmbio flutuante.

\subsection{Procedimentos de pesquisa}

A amostra de dados utilizada neste estudo, o qual busca analisar a influência do IED no crescimento do produto total dos setores da indústria brasileira que receberam investimentos estrangeiros, é composta por dados restritos às divisões nas indústrias de transformação brasileira para o período pós-abertura comercial (1996 a 2009).

A fim de normatizar e trazer todos os valores monetários utilizados neste trabalho para a mesma base, ano de 2009 , foram realizados os seguintes procedimentos. Os fluxos de IED informados pelo BACEN, para o período em análise, que estavam em milhões de dólares (US\$), foram transformados em reais (R\$) pela cotação do dólar do final de cada período. Em seguida, os dados foram deflacionados pelo Índice de Preços ao Consumidor 
Amplo (IPCA), para valores de 2009 e convertidos em dólares pela cotação em 31 de dezembro de 2009 (R\$ 1,7404). Para tais procedimentos foram consultadas as bases de dados do IPEADATA. Os demais valores monetários foram deflacionados pelo IPCA e convertidos em dólares de acordo com a taxa de câmbio comercial para venda - final do período de 2009 (R\$1,7404) (IPEA, 2013).

Com os microdados coletados junto à Relação Anual de Informações Sociais (RAIS), coordenada pelo Ministério do Trabalho e Emprego (M.T.E.) foram identificados, também, o número de trabalhadores com vínculo ativo em 31 de dezembro e seu respectivo nível de escolaridade, conforme exposto no Quadro 1.

Da Pesquisa Industrial Anual (PIA - Empresa), do IBGE foram coletados os dados sobre setores de atividades econômicas ligadas à indústria de transformação de acordo com a Classificação Nacional de Atividades (CNAE), estabelecida pela Comissão Nacional de Classificação (CONCLA) do Ministério do Planejamento, Orçamento e Gestão obedecendo à normatização internacional. Os dados da PIA - Empresa, seguem a seguinte estrutura: para o período de 1996 a 2006, os dados foram coletados da "seção D" da CNAE em sua versão 1.0, enquanto que para os anos de 2007 a 2009, foram coletados de acordo com a "seção C", da CNAE versão 2.0. Esta seção engloba as atividades que envolvem a transformação física, química e biológica de materiais, substâncias e componentes com a finalidade de se obter produtos novos (IBGE, 2007).

Para esta pesquisa foi realizada a agregação de alguns setores, conforme mostra o Quadro 3. Essa agregação teve por objetivo adequar a coleta de dados para as duas CNAE's, sem perda de rigor metodológico. Optou-se por estudar somente os setores que receberam mais de 1\% de IED para o período de 1996 a 2009.

Exceção para o setor Confecção de Artigos do Vestuário e Acessórios que foi incorporado ao setor Fabricação de Produtos Têxteis. Para a estimação do modelo foi necessária a compatibilização entre setores, conforme o Quadro 2.

Quadro 2 - Agregação dos setores da atividade econômica - Indústria da transformação

\begin{tabular}{|l|c|c|l|}
\hline Código & CNAE 1.0 & CNAE 2.0 & \multicolumn{1}{|c|}{ Denominação adotada na pesquisa } \\
\hline 1 & 15 & $10+11$ & Fabricação de produtos alimentícios e bebidas \\
2 & $17+18$ & $13+14$ & Fabricação de produtos têxteis e confecções \\
3 & 21 & 17 & Fabricação de celulose, papel e produtos de papel. \\
4 & 23 & 19 & Fabricação de coque, de produtos derivados do petróleo e de \\
biocombustíveis. \\
5 & 24 & $20+21$ & Fabricação de produtos químicos \\
6 & 25 & 22 & Fabricação de borracha e plástico \\
7 & 26 & 23 & Fabricação de produtos minerais não metálicos \\
8 & 27 & 24 & Metalurgia básica \\
9 & 28 & 25 & Fabricação de produtos de metal, exceto máquinas e equipamentos. \\
10 & $30+32+33$ & 26 & Equipamentos de informática, produtos eletrônicos e ópticos. \\
11 & 31 & 27 & Fabricação de máquinas, aparelhos e materiais elétricos. \\
12 & 29 & 28 & Fabricação de máquinas e equipamentos \\
13 & 34 & 29 & Fabricação de veículos automotores, reboques e carrocerias. \\
14 & 35 & 30 & Fabricação de outros equipamentos de transporte \\
\hline
\end{tabular}

Fonte: Adaptado do IBGE (2012). 
p. 29 - O diferencial de salários de setores selecionados da indústria brasileira na atração do investimento estrangeiro direto no Brasil entre 1996 a 2009

$\mathrm{Na}$ agregação realizada houve a exclusão dos seguintes setores: Edição, Impressão e Reprodução de Gravações; Fabricação de Produtos de Madeira; Fabricação de Móveis e Indústrias Diversas; Fabricação de Produtos de Fumo; Reciclagem; Preparação de Couros e Fabricação de Artefatos de Couro, Artigos de Couro e Calçados.

\section{O MODELO EMPÍRICO DE REGRESSÃO}

O objetivo deste trabalho é investigar a influência do IED no crescimento e desenvolvimento econômico do Brasil, por meio da interação com o mercado de trabalho da indústria de transformação, bem como a influência da taxa Selic ${ }^{3}$ e variação cambial, no período de 1996 a 2009. O modelo empírico adotado nesta parte do modelo teórico de Vu e Noy (2009) e, uma vez adaptado à realidade brasileira, de acordo com Oliveira, Maia e Devidé Junior (2014), cujo modelo empírico apresenta a seguinte descrição:

$$
\begin{aligned}
& V T P_{i t}=\beta_{0_{i t}}+\beta_{1} T R_{i t}+\beta_{2} I I_{i t}+\beta_{3} I E D_{i t}+\beta_{4} I E D T R_{i t}+ \\
& \beta_{5} \text { energia }_{i t}+\beta_{6} \text { dcambio }+\varepsilon_{i t}
\end{aligned}
$$

Em que:

$V T P_{i t}=$ valor total da produção da indústria de transformação no Brasil;

$T R_{i t}=$ total de trabalhadores com vínculo empregatício;

$I I_{i t}=$ investimento interno realizado;

$I E D_{i t}=$ fluxo de investimento estrangeiro direto;

$I E D T R_{i t}=$ interação entre valor do fluxo do IED e número de trabalhadores;

energia ${ }_{i t}=$ consumo de energia;

dcambio = variável dummy para o regime cambial.

$\varepsilon_{i t}=$ erro idissioncrático do modelo;

$i=$ setor da indústria, $\operatorname{com} i=1, \ldots, N$;

$t=$ unidades de tempo, com $t=1, \ldots, T$.

$\beta=$ parâmetros do modelo que descrevem as direções e as influências da relação entre valor total da produção dos setores e fatores usados para determinar o VTP.

De acordo com Oliveira, Maia e Devidé Júnior (2014), a equação de maior significância foi a que considerou a interação do IED com os salários dos trabalhadores mais qualificados e menos qualificados (ver quadro 2). O método de dados em painel adotado é o balanceado, formado inicialmente por cinco variáveis, conforme exposto na

\footnotetext{
3 Segundo Assaf Neto (2013, p. 64) "a taxa Selic representa a média de juros das operações diárias de financiamentos realizadas pelas instituições no mercado monetário, sendo as operações lastreadas em Títulos Públicos Federais. Os negócios são registrados e controlados pelo Sistema Especial de Liquidação e Custódia (Selic)". Para fins deste estudo utilizou-se a média da taxa Selic anualizadas. Somou-se as taxas determinadas pelo Comitê de Política Monetária (Copom), realizadas pelo Banco Central do Brasil, e seguida as mesmas foram divididas pelo número de reuniões realizadas entre os anos de 1996 a 2009.
} 
Equação (5), juntamente com duas variáveis de controle, quais sejam, consumo de energia e uma variável dummy para indicar o regime cambial no Brasil.

A partir da análise da mão de obra empregada no setor industrial, observou-se que há um maior número de trabalhadores com baixa qualificação da mão de obra. Por outro lado, como era esperado, o montante de salários pagos aos trabalhadores mais qualificados é superior aos dos menos qualificados.

No Brasil, os setores industriais que mais empregam no período de 1996 a 2009, são Fabricação de Alimentos e Bebidas e Fabricação de Produtos Têxteis e Confecção. Readaptando o modelo empírico, desta vez incluindo a interação entre o investimento interno e IED com a taxa Selic e a variação cambial para a determinação da influência das variáveis explicativas sobre o produto, o modelo apresenta a seguinte configuração:

$$
\begin{aligned}
& \operatorname{lnVTP} P_{i t}=\alpha+\beta_{1} \ln w q_{i t}+\beta_{2}{\ln w m q_{i t}}_{1}+\beta_{3} \operatorname{lnI} I_{i t}+\beta_{4}{\operatorname{lnII} \_c a m b i o_{i t}}+ \\
& \beta_{5} \text { lnII_selic }_{i t}+\beta_{6} \operatorname{lnIED} D_{i t}+\beta_{7} \operatorname{lnIEDwq_{it}}+\beta_{8} \operatorname{lnIEDwmq_{it}}+ \\
& \beta_{9} \text { lnIED_cambio } i t+\beta_{10} \text { lnIED_selic }_{i t}+\beta_{11} \text { lnenergia }_{i t}+\beta_{12} \text { dcambio }+\varepsilon_{i t}
\end{aligned}
$$

O modelo empírico completo abrange a interação entre as principais variáveis e suas hipóteses, quais sejam, os salários dos trabalhadores qualificados e menos qualificados e os salários pagos, no período analisado. Desta forma, verifica-se a análise das seguintes variáveis logarítmicas: $\ln w q_{i t}$ salários dos trabalhadores qualificados; $\operatorname{lnwm}_{i t}$ salários dos trabalhadores menos qualificados; InII_cambio ${ }_{i t}$ interação entre

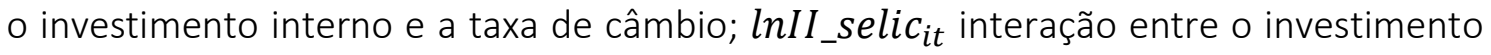
interno e taxa Selic; $\operatorname{lnIED} w q_{i t}$ interação entre o investimento estrangeiro direto e os

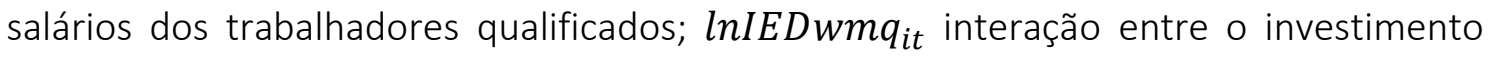
estrangeiro direto e o salário dos trabalhadores menos qualificados; $\operatorname{lnIED\_ cambio}{ }_{i t}$ interação entre investimento estrangeiro direto e a taxa de câmbio; $\operatorname{lnIED\_ selic}$ it interação entre o investimento estrangeiro direto e a taxa Selic;

Nesta configuração, observou-se também, além das interações entre os salários dos trabalhadores mais qualificados e menos qualificados com o IED, a interação entre o investimento interno e o investimento estrangeiro direto com a variação cambial e a taxa Selic. Na próxima seção, serão apresentados os resultados encontrados.

\section{ANÁLISE DOS RESULTADOS}

Como a equação (6) estimada apresentou autocorrelação serial entre os resíduos, houve a necessidade de estimar o modelo em primeira diferença e o modelo passou a ter 182 observações. Os resultados dos coeficientes, bem como o valor $p$ (entre parênteses), das variáveis utilizadas na equação (6) corrigida estão representados na equação (7). 
p. 31 - O diferencial de salários de setores selecionados da indústria brasileira na atração do investimento estrangeiro direto no Brasil entre 1996 a 2009

$$
\begin{aligned}
& \ln V \hat{T} P_{i t}=\underset{(0,0000)}{0,0421}+\underset{(0,0000)}{0,5542} \ln w q-\underset{(0,0000)}{0,3852} \ln w m q+\underset{(0,0000)}{0,4015} \ln I I+\underset{(0,0050)}{0,0249} \ln \text { IIcambio }+ \\
& +\underset{(0,0000)}{0,3405} \ln I I s e l i c+\underset{(0,0000)}{0,197} \ln I E D-\underset{(0,0000)}{0,5086 \ln I E D w q}+\underset{(0,0000)}{0,696 \ln I E D w m q-} \\
& \underset{(0,0010)}{0,0233 \ln I E D \text { cambio }} \underset{(0,0000)}{0,3826 \ln \text { IEDselic }}+\underset{(0,0000)}{0,1640 \ln } \text { energia } \underset{(0,0000)}{0,0391} \text { dcambio }
\end{aligned}
$$

O valor do coeficiente da variável In wq, indica que, para um aumento de $1 \%$ nos salários dos trabalhadores qualificados, o valor total da produção dos setores da indústria cresceu 0,5542\%, tudo o mais permanecendo constante. Esse estimador é estatisticamente significativo e o seu resultado confirma a existência de produtividade dos trabalhadores qualificados.

O estimador da variável In wmq indica que para cada aumento em 1\% haverá um decréscimo no total da produção dos setores da indústria em 0,3852\%, sinalizando que o IED busca o diferencial de salários pago à mão de obra menos qualificada, este sinal negativo era esperado, uma vez que as empresas multinacionais buscam a internacionalização da sua produção na tentativa de reduzir custos. Assim, corrobora-se a afirmação de Markusen e Maskus (2001), ao relatarem que o IED será direcionado para países ou regiões com menor relação da mão de obra qualificada sobre a mão de obra total. Neste caso, quanto maiores os salários, menor será a interação entre IED e salários dos trabalhadores qualificados no VTP setorial.

O acesso ao crédito, por meio da análise do investimento interno na indústria de transformação no Brasil, para o período em análise, apresentou-se como esperado, uma vez que estabilidade da economia possibilitou 0,4015\% de aumento sobre a variável dependente. Este resultado está de acordo com Lall (1998 apud NOORRBAKHSH; PALONI; YOUSSEF, 2001) ao afirmar que a infraestrutura em países em desenvolvimento atrai IED. Já Blomstrom e Kokko (2003) destacam que as empresas locais devem ter incentivos para buscar os transbordamentos tecnológicos oriundos das EMN's. Além disso, esta variável pode ser considerada uma das que sustentaram a atual fase de crescimento econômico do Brasil.

A interação entre o investimento interno e a taxa de câmbio mostrou-se positiva sobre a variável dependente em 0,0249\%. O mesmo resultado positivo pode-se observar na interação entre o investimento interno e a taxa Selic, ou seja, 0,3405\%. A variável que representa somente o IED promoveu crescimento no VTP dos setores, ou seja, informa que somente o IED foi capaz de promover o crescimento da variável dependente do modelo, apresentando influência positiva (0,197\%).

A interação entre o IED e os salários dos trabalhadores qualificados indica sinal negativo, conforme esperado, $-0,5086 \%$. Esse resultado confirma os resultados do trabalho de Mello Júnior (1999), uma vez que o autor defende que o IED potencializa o crescimento econômico, no entanto, depende do grau de complementaridade na economia receptora. No caso do Brasil, pode-se afirmar que esse complemento é a abundância da parcela de mão de obra menos qualificada sobre a mão de obra total. Fato 
que mostra que as empresas multinacionais preferem países com mão de obra barata. Isso é verificado na próxima variável, ou seja, a interação entre IED e o salário dos trabalhadores menos qualificados apresentou sinal positivo de 0,696\%.

A interação entre o IED e a variável câmbio mostrou-se negativo em 0,0233\%. Enquanto a interação entre IED e taxa Selic foi de 0,3826\%. O resultado do coeficiente para o consumo de energia apresenta, além do sinal positivo esperado, a influência positiva $(0,164 \%)$ sobre a variável dependente.

Dentre as variáveis que apresentaram influência negativa sobre o VTP, destacase, que mede a influência dos salários dos trabalhadores menos qualificados (-0,3852\%).

Finalmente, o coeficiente da variável dummy, para o período em questão, utilizada para indicar o regime cambial adotado pela autoridade monetária no Brasil, para o período analisado, apesar de negativo, mostrou-se significativo, confirmando que a mudança do regime cambial em janeiro de 1999, não chegou a influenciar o crescimento do VTP dos setores analisados, visto que seu valor foi relativamente baixo (-0,0391\%). Porém, manteve o contato econômico do Brasil com os países desenvolvidos, via IED, principalmente, com os Estados Unidos e Países Baixos (Holanda).

Após a análise das variáveis, que remetem ao modelo robusto e a descrição dos dados estatísticos, bem como a verificação da significância econômica dos mesmos, a seção seguinte apresentará as considerações finais.

\section{CONSIDERAÇÕES FINAIS}

A partir dos anos 1990 o Brasil promoveu uma série de mudanças estruturais em sua economia. Um dos objetivos do governo com estas mudanças era de tornar o país um forte receptor do fluxo de capitais de longo prazo, investimento estrangeiro direto (IED), e assim, modernizar a economia. O resultado foi, por um lado, uma expressiva integração tecnológica e financeira entre a economia brasileira e a economia dos países investidores e, por outro lado, maior vulnerabilidade às crises externas.

O aumento do ingresso do IED junto à economia brasileira, já nos primeiros anos após a abertura comercial, na década de 1990, ocorreu por meio de incentivos, tais como: a alta rentabilidade (taxas de juros elevadas), processo de privatizações, incentivos fiscais, acesso a matérias-primas, diferenciais de salários em relação a outros países e mão de obra barata em abundância. A partir dessa contextualização, a motivação deste estudo foi buscar entender quais mecanismos acima citados, podem ser considerados pontualmente importantes na atração do IED à econômica brasileira no período recente.

Os principais resultados desta pesquisa indicaram que o IED afeta o crescimento dos setores da indústria, assim como os salários dos trabalhadores qualificados da indústria da transformação brasileira influenciaram positivamente no crescimento do produto dos seus respectivos setores, no entanto, esta variável não influencia na atração de IED, uma vez que quando se observa a interação do IED com os salários dos trabalhadores qualificados verifica-se que os investimentos externos buscam os salários dos trabalhadores menos qualificados. (OLIVEIRA, MAIA E DEVIDÉ JÚNIOR, 2014). Os trabalhadores menos qualificados da indústria no Brasil influenciam negativamente no 
p. 33 - O diferencial de salários de setores selecionados da indústria brasileira na atração do investimento estrangeiro direto no Brasil entre 1996 a 2009

VTP dos setores, entretanto, a interação com o IED demonstra que este tipo de investimento busca a redução de custos por meio de salários mais baixos ofertados no mercado de trabalho.

As taxas de juros (Selic) e a variação cambial, quando se realiza investimento interno, demonstram que este tipo de investimento usufruiu das políticas monetárias no Brasil em período recente; enquanto que estas mesmas variáveis ao interagirem com o IED demonstram que estas não foram atrativas.

Diante de tais resultados recomenda-se políticas públicas que promovam a qualificação da mão de obra, de forma a aumentar o valor bruto da produção, via maior produtividade e desenvolvimento do setor industrial.

Tais resultados mostram a importância desta pesquisa no sentido de indicar que o IED dos países investidores não busca apenas incentivos fiscais e acesso a matériasprimas, buscam também um complemento que é a mão de obra barata e abundante no Brasil.

\section{REFERÊNCIAS BIBLIOGRÁFICAS}

ARAÚJO, E.; BRUNO, M.; PIMENTEL, D. Regime cambial e mudança estrutural na indústria de transformação brasileira: evidências para o período (1994-2008). Revista de Economia Política, São Paulo, v. 32, n. 3, p. 424-444, jul./set. 2012. Disponível em: <http://www.scielo.br/pdf/rep/v32n3/05.pdf>. Acesso em: 5 maio 2015.

ASSAF NETO, A. Mercado financeiro. 10. ed. São Paulo: Atlas, 2011.

BANCO CENTRAL DO BRASIL. Censo de capitais estrangeiros no país: resultados para 2010 e 2011. Brasília, 2012. Disponível em: <http://www.bcb.gov.br/Rex/CensoCE/port/ Censo\%20de\%20Capitais\%20Estrangeiros\%20-\%20resultados\%2020112012.pdf>. Acesso em: 1 jun. 2015.

Séries temporais: tabelas especiais. Disponível em: <http://www.bcb.gov.br/? INVED>. Acesso em: 12 abr. 2015.

BLOMSTROM, M.; KOKKO, A. The economics of foreign direct investment incentivs. National Bureau of Economic Research, Cambridge, v. 9489, 2003. Disponível em: <http://www.nber.org/papers/w9489>. Acesso em: 1 abr. 2015.

BRASIL. Ministério do Trabalho e Emprego. Relação anual de informações sociais: RAIS. Brasília, 2012. Disponível em: <http://portal.mte.gov.br/portal-pdet/>. Acesso em: 25 abr. 2015.

BRESSER-PEREIRA, L. C.; MARCONI, N. Existe doença holandesa no Brasil? 2008. Disponível em:

<http://www.bresserpereira.org.br/papers/2008/08.14.Existe.doen\%C3\%A7a. holandesa.comNelson.Marconi.5.4.08.pdf>. Acesso em: 5 maio 2015.

CARNEIRO, R. Desenvolvimento em crise: a economia brasileira no último quarto do século XX. São Paulo: Ed. da Unicamp, 2002. 
FRANCO, G. H. B. Investimento estrangeiro direto (IED) no Brasil 1995-2004: "passivo externo" ou "ativo estratégico"? 2005. Disponível em: <http://www.econ.pucrio.br/gfranco/CIDEC_IDE\%20no\%20Brasil.PDF>. Acesso em: 22 fev. 2015.

O Brasil e a globalização na primeira década após o Plano Real: os censos de capital estrangeiro no Brasil, 1995, 2000 e 2005. In: SEMINÁRIO NOVOS DILEMAS DE POLÍTICA ECONÔMICA, 2010, Rio de Janeiro. Anais... Rio de Janeiro: Instituto de Política Econômica, 2010. Disponível em: <http://www.economia.pucrio.br/gfranco/ Terceiro\%20censo_artigo\%20livro \%20DDC_final\%5B1\%5D.pdf>. Acesso em: 24 abr. 2015.

GONÇALVES, J. E. P. Empresas estrangeiras e transbordamentos de produtividade na indústria brasileira: 1997 a 2000. 2005. 108 f. Dissertação (Mestrado em Economia) - Universidade Estadual de Campinas, Campinas, 2005.

IBGE. Pesquisa Industrial Anual - PIA Empresa. Rio de Janeiro, 2012.

Classificação Nacional de Atividade Econômica: CNAE 2.0. Rio de Janeiro, 2007. CD-ROM.

INSTITUTO DE ESTUDOS PARA DO DESENVOLVIMENTO INDUSTRIAL - IEDI. Investimento estrangeiro direto no Brasil: um panorama. 2006. Disponível em: <http://www.iedi.org.br/admin_ori/pdf/20060804_ide.pdf>. Acesso em: $22 \mathrm{fev}$. 2015.

INSTITUTO DE PESQUISA ECONÔMICA APLICADA - IPEA. Inserção internacional brasileira: temas de economia internacional/IPEA. Brasília, 2010.

- Taxa de câmbio comercial para venda: real (R\$) / dólar americano (US\$) - fim período. 2013. Disponível em: <http://www.ipeadata.gov.br/>. Acesso em: 22 maio 2015.

JORGE, M. F. Investimento estrangeiro direto e inovação: um estudo sobre ramos selecionados da indústria brasileira. 2007. 86 f. Dissertação (Mestrado em Economia) - Faculdade de Ciências Econômicas da Universidade Federal do Rio de Janeiro, Rio de Janeiro, 2007.

KRUGMAN, P. R.; OBSTFELD, M. Economia internacional: teoria e política. 8. ed. São Paulo: Pearson Prentice Hall, 2010.

LAPLANE, M.; SARTI, F. Investimento estrangeiro direto e o impacto na balança comercial nos anos 90. Texto para Discussão, Rio de Janeiro, n. 629, 1999. Disponível em: <http://www.ipea.gov.br/pub/td/tda1999a.html>. Acesso em: 22 fev. 2015.

MARKUSEN, J. R.; MASKUS, K. E. Multinational firms: reconciling theory and evidence. In: BLOMSTROM, M.; GOLDBERG, L. S. (Ed.). Topics in empirical international economics: a festschirift in horor of robert e. lipsey. Chicago: Universit of Chicago Press, 2001. p. 71-98. Disponível em: <www.nber.org/chapters/c10579. pdf>. Acesso em: 22 fev. 2015.

NOORBAKHSH, F.; PALONI, A.; YOUSSEF, A. Human capital and FDI inflows to developing countries: new empirical evidence. World Development, Oxford, v. 29, n. 9, p. 
p. 35 - O diferencial de salários de setores selecionados da indústria brasileira na atração do investimento estrangeiro direto no Brasil entre 1996 a 2009

1593-1610, set. 2001. Disponível em: <http://www.sciencedirect.com/science/ article/pii /S0305750X01000547>. Acesso em: 22 fev. 2015.

OLIVEIRA, G. S.; MAIA, K.; DEVIDÉ JÚNIOR, A. Sectoral analysis of foreign direct investment and growth in Brazil from 1996 to 2009. In: DANG, H. et al. (Org.). Transnational corporations and development in Brazil: challenges and opportunities. Maringá: TNC, 2014. v. 4, p. 159-174.

RIBEIRO, M. S. Investimento estrangeiro direto e remessas de lucros e dividendos no Brasil: estratégias microeconômicas e determinantes macroeconômicos (2001 - 2004). 2006. 155 f. Tese (Doutorado em Economia) - Universidade Federal de Minas Gerais, Belo Horizonte, $2006 . \quad$ Disponível em: <https://www.cedeplar.ufmg.br/economia/teses/2006/ Mauro_Sudano_Ribeiro.pdf >. Acesso em: 6 fev. 2015.

SIMONSEN, M. H.; CYSNE, R. P. Macroeconomia. 3. ed. São Paulo: Atlas, 2007.

UNITED NATIONS CONFERENCE ON TRADE AND DEVELOPMENT - UNCTAD. Investimentos estrangeiros diretos. 2013. Disponível em: <http://unctadstat. unctad.org/ReportFolders/reportFolders.aspx>. Acesso em: 12 fev. 2015.

VU, B.; NOY, I. Sectoral analysis of foreign direct iinvestment and growth in the developed countries. Journal of International Financial Markets, Oxford, v. 19, n. 2, p. 402413, abr. 2009. Disponível em: <http://ideas.repec.org/a/eee/intfin/v19y2009i2p402-413.html>. Acesso em: 22 fev. 2015.

WORD BANK. Word debt tables: external finance for developing countries. Washington, 1996. v. 1 (Analysis and Summary Tables). Disponível em: <http://www.worldbank.org/reference/>. Acesso em: 12 jun. 2015. 